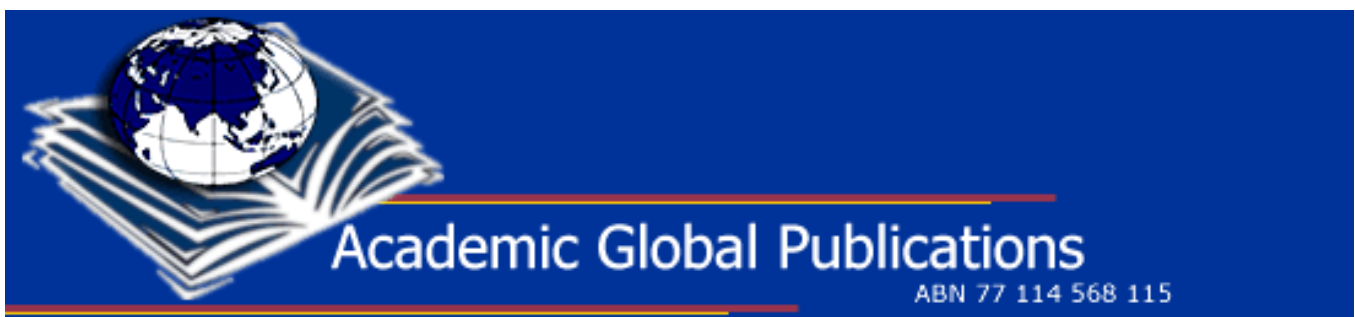

International Technology Management Review

Volume 2 Number 1 (October) 2009

<http://www.academicglobalpublications.com/itmr/>

\title{
E-Governance Implementation in Metropolitan and Rural Areas of Bangladesh: An Illustrative Prototype
}

\section{Gazi Zahirul Islam}

Lecturer,

Department of Computer Science and Engineering,

Primeasia University,

Dhaka, Bangladesh.

Email: zahircuet@gmail.com

Phone: +88 01711937820 


\begin{abstract}
Title: E-Governance Implementation in Metropolitan and Rural Areas of Bangladesh: An Illustrative Prototype
\end{abstract}

Keywords: ICT, VPN, Public network, Private network, Baud rate, Dial-up network

Category of paper: Conceptual paper

Purpose of the paper: The goal of this paper is to implement e-governance in a flexible and cost effective manner to suit with current ICT infrastructure in Bangladesh to provide better information and service delivery of the government to the public; and hence promote democratic practices through public participation and consultation.

Findings: This paper depicts and implements a model of e-governance for urban and rural areas of Bangladesh. The project deeply considered existing ICT infrastructure in Bangladesh and put effort to implement the model in a cost effective and flexible manner. A clear, comprehensive layout and network architecture for rural and city areas is also provided. We also describe complementary tasks such as database implementation, system development, web related task etc. for e-governance implementation.

Implication for practice: This paper could provide important guidelines and information to government and others who deal with e-governance.

Value of the paper: This paper will be of interest to government, academics and system engineers.

\title{
Number of pages: 17
}

\section{Number of tables/figures: 9}

Section headings: Abstract, Introduction, Literature review, Layout design, Network Architecture, Data rate specification, Database structure, Software development, System implementation, Constraints and recommendations, Conclusion.

(C) 2009 Academic Global Publications P/L. This work is copyright. You may download and print only one paper copy from this electronic file for your personal use only, from which you may not make any further paper copies.

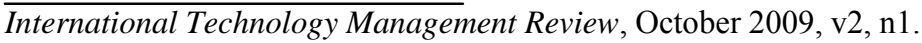




\title{
Academic Global Publications
}

\author{
International Technology Management Review \\ Volume 2 Number 1 (October) 2009 \\ <http://www.academicglobalpublications.com/itmr/>
}

\section{E-Governance Implementation in Metropolitan and Rural Areas of Bangladesh: An Illustrative Prototype}

\section{Gazi Zahirul Islam}

\begin{abstract}
Several developing countries including Bangladesh are realizing the role ICT (Information \& Communication Technology) can play in the governance sector, and are putting into practice innovative e-governance models that may be technologically simple but are drastically changing the way information is distributed in the society. This paper depicts and implements a model of e-governance for urban and rural areas in Bangladesh. The project deeply considered existing ICT infrastructure in Bangladesh and put effort to implement the model in a cost effective and flexible manner. A clear, comprehensive layout and network architecture for rural and city areas is given separately. We also described complementary tasks such as database implementation, system development, web related task etc. for e-governance. The main objective of the project is to implement e-governance in an easy and cost effective way to suit with existing ICT infrastructure in Bangladesh to provide better information and service delivery of government to the people.
\end{abstract}

\section{Introduction}

Lack of information and communication infrastructure results in people having to waste time and money. Lack of clarity in processes, and corruption and mismanagement in systems and operations is rampant in Bangladesh. The inaccessibility of information affects the rural poor more than other sectors of the community. Similarly, lack of market information (on commodity prices, various input suppliers, etc.) leads to loss of income and exploitation of rural entrepreneurs by middlemen. Such exploitation and losses further marginalize small and marginal farmers and village artisans. In this context, Information and Communication Technologies can play a significant role in making information available at a reasonable cost. E-governance is the public sector's use of information and communication technologies with the aim of improving information and service delivery, encouraging citizen participation in

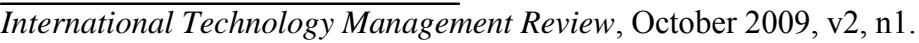


the decision-making process and making government more accountable, transparent and effective (DG Communities, 2005). Bangladesh and many other developing countries are apprehending the importance of ICT in the governance arena, and are putting into practice innovative e-governance models that might be technologically simple but are abruptly changing the way information is distributed to the public (Global Information Infrastructure Commission, 2005). In this paper we delineate a model of e-governance for rural and city areas of Bangladesh.

The project deeply considered current ICT infrastructure in Bangladesh and tried to implement the project in a cost effective manner. A clear, comprehensive layout for urban and rural areas is drawn separately and is shown in section 'layout design' of this paper. Since, in Bangladesh government telephone line is the most widely spread data communication line; we have chosen a VPN (virtual private network) model for implementing e-governance and is explained in section 'network architecture'. In section 'software development' we described complementary tasks such as database implementation, system development, web related task etc. to establish a full-fledged model of e-governance. We have developed sample database, forms and web pages which views are included in this paper. The goal of this paper is to implement e-governance in a flexible and cost effective manner to suit with current infrastructure in Bangladesh to provide better information and service delivery of the government to the public; and hence promote democratic practices through public participation and consultation.

\section{Literature review}

E-government refers to the delivery of government services and information to the public, using electronic means to transform the way it serves its constituents (Murthy, Kumar, 2003). E-government must be on governance and not just IT; on citizens and their needs and not just on computers; on transforming the process not on translating the process; and on software not on just hardware and focus on people but not on systems (DigitalGovernance.org Initiative, 2005). Thus, e-government is not just 'e' but about facilitating the system by 'e' and getting it to work for citizens to benefit them in their daily activities of practical life (E-Democracy, EGovernance and Public Network, 2005).

\section{Goals of e-governance}

- Improve the internal organizational processes of governments

- Provide better information and service delivery

- Increase government transparency in order to reduce corruption

- Reinforce political credibility and accountability

- Promote democratic practices through public participation and consultation

- Focus on disadvantaged communities, who otherwise will be excluded

- Provide that information or service which otherwise will not be provided

- Create an outcome which in absence of ICT will not be produced efficiently or timely

Digital Governance models are continuously evolving, depending on the uses to which they are put into, the new ICT applications that are becoming possible, and most importantly, the changing political realities in the governance sphere. There are no rigid and finite models of Digital Governance. Since these models are based on strategic use of information, the

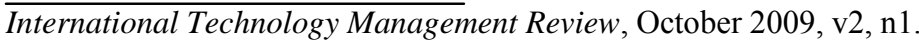


possibilities are endless, depending on how innovative and imaginative the governments, the citizen groups, and the international development agencies can be.

Technology does play an important role- the role of making possible strategic use of information. E-governance is not about technology; instead it is about identifying what are the key governance needs that need to be fulfilled, and then envisaging models by which these needs could be fulfilled appropriately and with ease. ICT plays the important role of powering these models, making possible information flows (in volumes and speeds) using conventional communication means.

Several developing countries are realizing the role ICT can play in the governance sector, and are putting into practice innovative e-Governance models that may be technologically simple but are drastically changing the way information is distributed in the society. Based on primary experimentation and secondary research, some generic Digital Governance models which are being practiced in developing countries have been identified. All these models benefit from the intrinsic characteristics of ICTs, which are:

- Enabling equal access to information to anyone who is a linked to the digital network.

- De-concentration of information across the entire digital network.

In simpler terms, information does not reside at any one particular level (or node) in Digital Governance Models but gets distributed across all the nodes.

\section{Layout design}

Like other developing countries, the infrastructure of ICT between rural and urban areas in Bangladesh is different (Islam, Jabiullah, Rahman, 2004). So, separate layout should be considered for cities and villages. Design of an e-governance scheme for a rural area involves many constraints such as connectivity, bandwidth and available infrastructure (Das, Sharma, Gogoi, 2004). In city areas the structure is stronger and easier to implement e-governance. By various scheme initiated by Government of Bangladesh, rural telephony penetrates into most of the remote villages of the country. This paper describes the design issues of a practical egovernance system for rural and urban areas. Emphasis was on giving a cost effective solution with minimal changes to the existing communication infrastructure and user-friendly interface to the system using English and Bengali Language. Also the issues like getting active network connection through dial-up modem have been taken into consideration.

\section{A. Layout for rural areas}

In rural areas District Commission Office (DCO) is the centre of control, where database server, web and application server, network hub etc. will be kept. Other areas are connected to District Commission Office. Kiosk or booth should be set up in different places for public to communicate with DCO office. We may choose Upazela Offices and Union Offices as the place to set up the kiosks. Without Upazela Office and Union Office a remote populated or important place may be choose to set up kiosk for ease of public. All kiosks should be equipped with at least a computer, a modem, telephone line and other equipments to communicate with DCO office. Figure 1 shows the layout of the model for rural areas. Upazela Office, Union Office and distant kiosk are directly connected to District Commission Office (DCO).

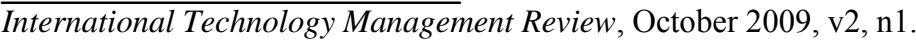


Figure 1: Layout for rural areas

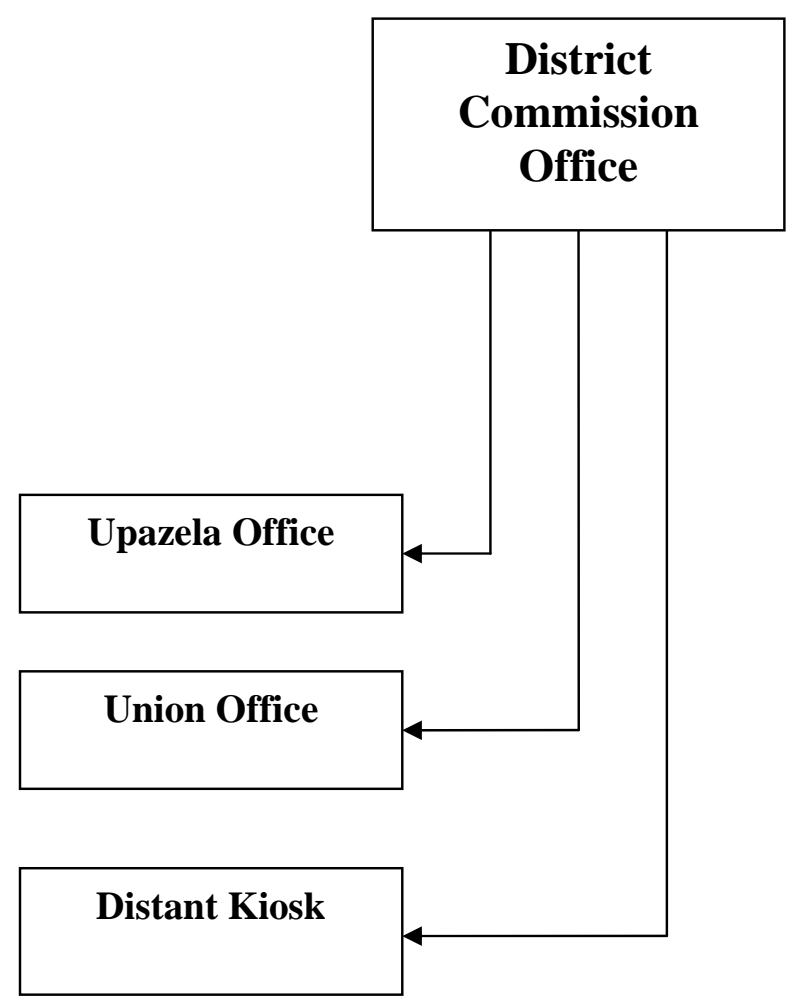

Source: Developed for this paper

\section{B. Layout for city areas}

The infrastructure of ICT in cities are substantial than rural areas. It is easier to implement egovernance in city areas than rural areas. We can easily divide a city area by wards. In every Ward Commission Office a kiosk has to be setup. Here, City Corporation Office (CCO) will take the control of governance (Dhaka City Corporation, 2006). Every kiosk is connected to the CCO. The equipments in the kiosk are more equipped and sophisticated in cities than rural villages. Figure 2 depicts the model. 
Figure 2: Layout for city areas

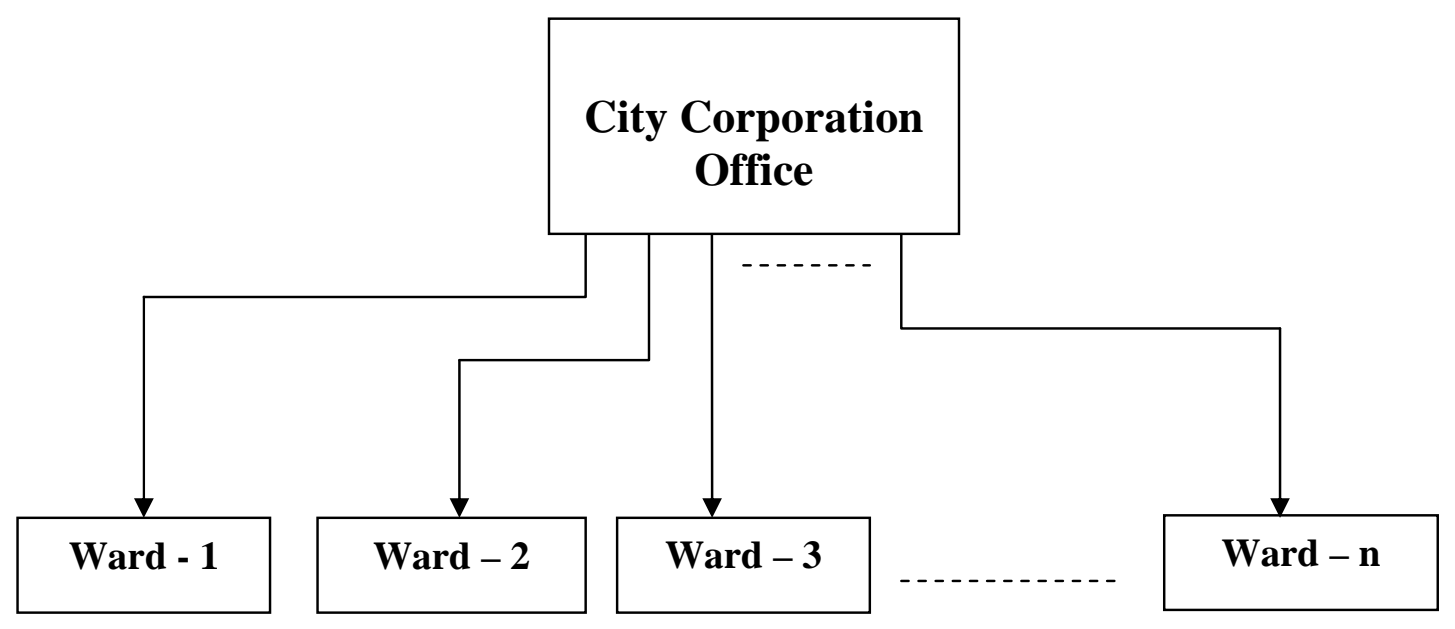

Source: Developed for this paper

\section{Network architecture}

There is a big gap between infrastructure needed for a pervasive e-governance and what is infact present in rural and city areas (Sharma, 2005). So, information and communication network designer needs to measure the success rate in terms of technological breakthrough of the system under design (Rajaraman, 2005). The concept of e-governance can be translated into practice by creating required ICT infrastructure and introduction of appropriate operational strategies. Following are the few ICT network scheme:

- Public Network

- Private Network

- Virtual Private Network (VPN)

A public network is owned and operated by a service provider similar to a telephone service. Any subscriber can use a pubic network to communicate with any other subscriber. One of the features of a public network is universal communication - a given subscriber's computer can communicate with any other subscriber's computer. The chief advantages of a public network are flexibility and the ability to use state-of-art networking without maintaining technical expertise. A public network is flexible because an arbitrary subscriber at an arbitrary location can connect to the network at any time. But the system can not provide sufficient security and it is not suitable for particular decisions or policies.

A network is said to be private if use of the network is restricted to the corporate or individual owner. The chief advantage of a private network is that the owner has complete control over both the technical decisions and policies. But a private network can be expensive to install and maintain. In addition to purchasing the network hardware, a corporation must hire and train a staff to install, manage, and operate the network. Special tools and maintenance equipment may also be needed.

A Virtual Private Network (VPN) combines the advantages of private and public networks by allowing a company with multiple sites to have the illusion of a completely private network International Technology Management Review, October 2009, v2, n1. 
and to use a public network to carry traffic between sites (Comer, 2004). In particular, although the company can use the public network as a link between its sites, VPN technology restricts traffic so that packets can travel only between the company's sites. Furthermore, even if an outsider accidentally receives a copy of a packet, VPN technology ensures that they cannot understand the contents.

To build a VPN, a company buys a special hardware and software system for each of its sites. The system is placed between the company's private networks and the public network. Each VPN system must be configured with the addresses of the VPN systems at other sites. Once such a configuration has been entered, the VPN system restricts packets. First, the VPN system at each site restricts incoming packets - no packet can enter the site unless the packet came from one of the company's other sites. Second, the VPN system at each site restricts outgoing packets - no packet can leave the site unless it is traveling to another one of the company's sites. As a result, once VPN software has been configured, the company's sites can only communicate with one another; they are cut off from the rest of the network.

We will choose a VPN model for implementing e-governance. The model will use government telephone line for data transmission. In our country government telephone line is the most widely spread data communication line. Actually, telephone network is the most suitable means for rural areas that can be used for implementing e-governance. So, we need to establish a dial-up communication line through government telephone line. Figure 3 shows the network structure for rural areas, where Upazela Office, Union Office and Distant Kiosk are connected to District Commission Office through the telephone line. It is not hard or complex to implement a Virtual Private Network (VPN) that could provide sufficient security for such a project. VPN can be implemented with a combination of easily acquirable hardware and software (Tanenbaum, 2004).

\section{Figure 3: Dial-up networks of rural areas}

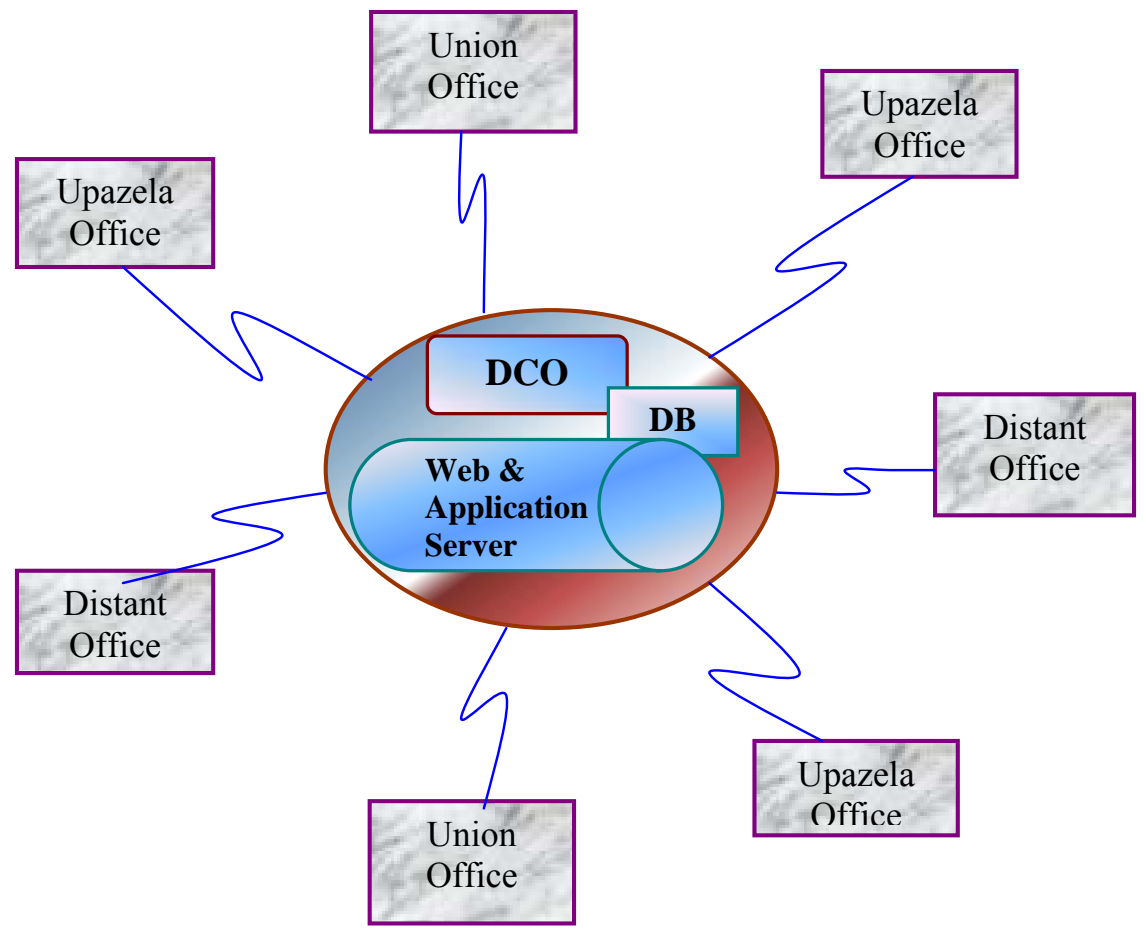

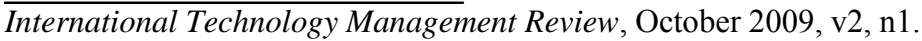


In city areas every ward offices are connected to City Corporation Office. Figure 4 shows the network structure for city areas. The communication medium of rural areas and city areas is same that is telephone line. Actually, more sophisticated medium and equipment may be implied in city area as the demand of city people is more than rural people. Since telephone line is available in every place in city and we consider a minimized cost, we designed the model with dial up telephone line as villages. Figure 4 shows the structure of city areas.

\section{Figure 4: Dial-up networks of city areas}

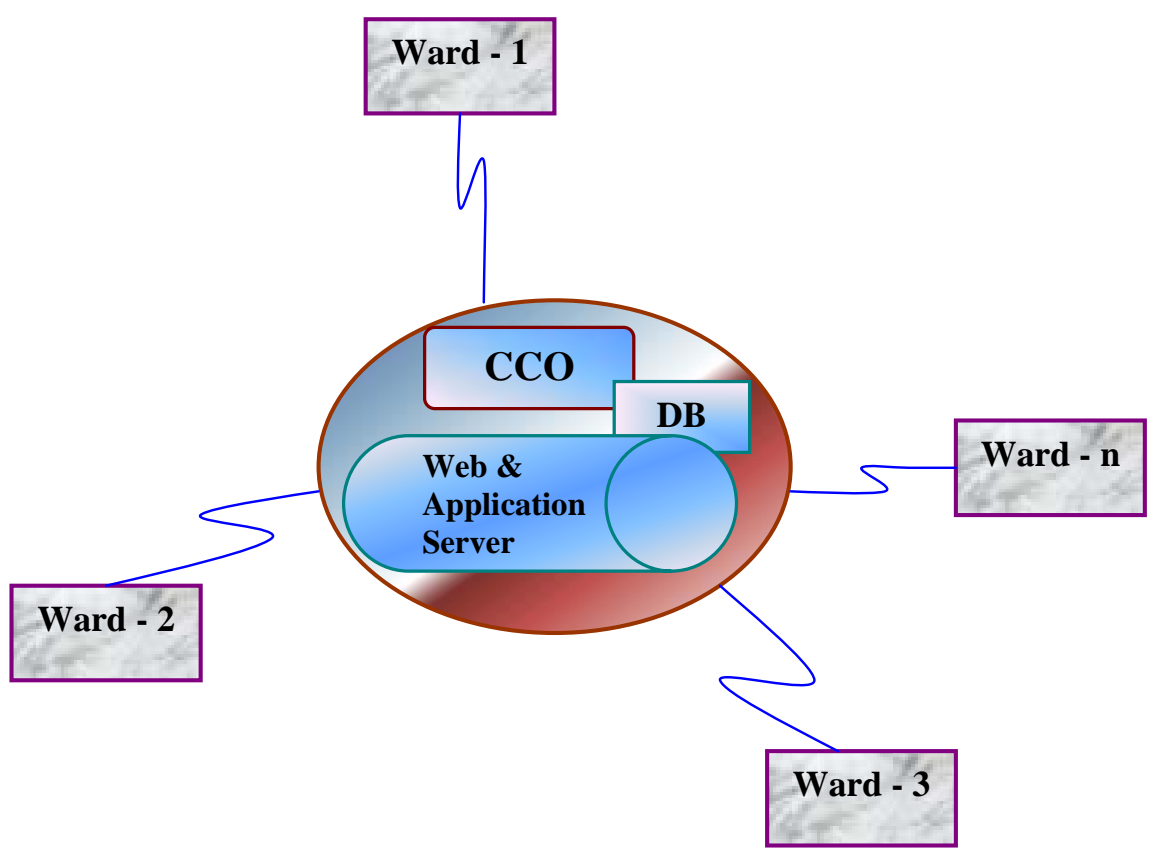

\section{Data rate specification}

Source: Developed for this paper

The bandwidth of the telephone line should be considered to implement the model. To reduce the bandwidth, only data fields are transmitted to store it in the main database. Data rate is the number of bits per second and Baud rate (B) is the number of characters per second. A character frame consists of 8 data bits and 1 stop bit. So, character frame length is 9 bits. If modem speed is set at $33600 \mathrm{bps}$, then Baud rate,

$\mathrm{B}=33600 / 9=3733$ characters per second

Therefore, 3733 characters per second can be transmitted through the telephone line. We consider that the worst case dial-up speed at distant places is at 26100 bps. Data will transmitted successfully at this rate as described in table 1 . 
Table 1: Data rate and dial-up speed

\begin{tabular}{|l|l|l|l|}
\hline Forms & Characters & $\begin{array}{l}\text { Required data } \\
\text { rate }\end{array}$ & $\begin{array}{l}\text { Worst case dial-up } \\
\text { connection }\end{array}$ \\
\hline Minimum field content & 300 & $2700 \mathrm{bps}$ & $26100 \mathrm{bps}$ \\
\hline Maximum field content & 2800 & $25200 \mathrm{bps}$ & $26100 \mathrm{bps}$ \\
\hline
\end{tabular}

Source: Developed for this paper

\section{Database structure}

There are different styles of database management and data warehousing systems, each characterized by the way data are defined and structured, called database architectures. There are several database architectures such as Hierarchical database, Network database, Relational database, Object-oriented, Multidimensional database and so on. We choose Relational database model for our project. Because it is the most common model and it is easy to implement. Most new applications are built using relational DBMSs, and many relational DBMS products exist.

The relational data model represents data in the form of tables. The relational model is based on mathematical theory and therefore has a solid theoretical foundation (Hoffer, Prescott, McFadden, 2004). The relational data model consists of the following three components:

1. Data structure: Data are organized in the form of tables with rows and columns.

2. Data manipulation: Powerful operations are used to manipulate data stored in the relations.

3. Data integrity: Facilities are included to specify business rules that maintain the integrity of data when they are manipulated.

\section{Software development}

To implement e-governance a huge class of software is needed in various developing stages. Many commercial softwares are available which should be purchased to implement the system. Of course, some software should be developed to provide desired services to the citizen. An important task is to create database. A large class of database is a significant criterion for such a project. One thing should be kept in mind during software development is that software should be flexible to use and be simple to suit with the existing communication infrastructure.

We have created sample databases, web pages and forms for our e-governance model (Hoffer, Prescott, McFadden, 2004). For convenience, we developed a virtual web site for Dhaka City Corporation. The real implementation would need rigorous analysis and planning to meet the people needs and corporation needs. We developed database, web site, and some forms for online job application. Figure 5 shows the view of the web site. The web pages are developed by html code and with the help of Microsoft Front Page.

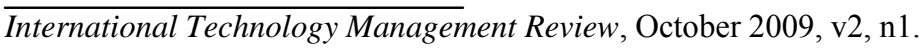


Figure 5: Web site of Dhaka City Corporation

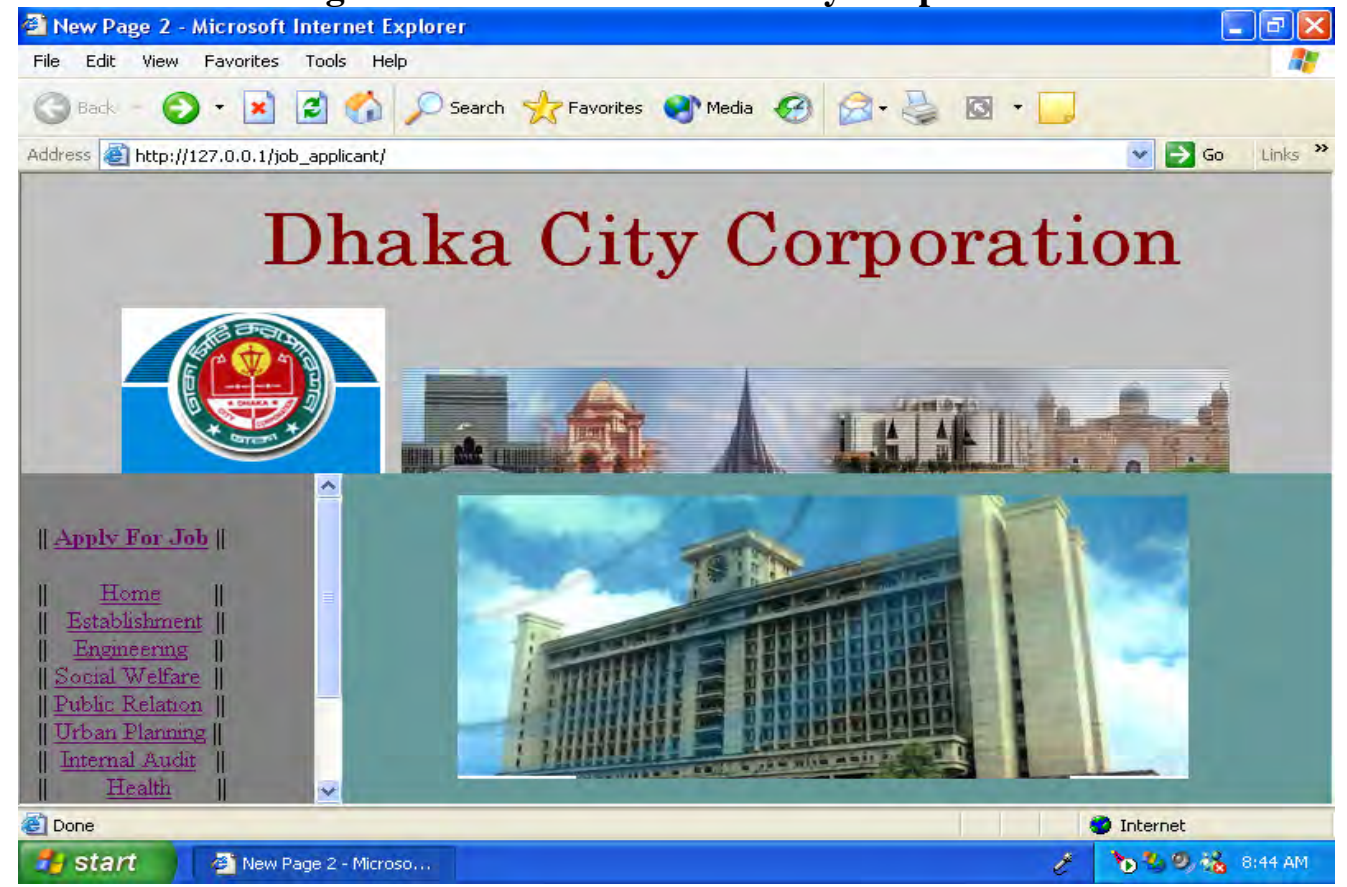

Source: Developed for this paper

There are several links of the main page of DCC website. The button "Apply for Job" is the link to the job application form. Clicking the button job form will appear. Users who are interested of the job they fill the form and submit online, then the data of the form is stored in the main database of the city corporation. We created a database named 'JOB_APPLICATION' with php and mysql software. Figure 6 shows first portion of the job application form. This portion required personal information and career \& application information about the intended candidate.

Figure 6: First portion of the of the job_applicant form

\begin{tabular}{||l||l||l||l||}
\hline \multicolumn{2}{|l|}{ PERSONAL INFORMATION } \\
\hline \hline User ID & 0004028 & & \\
\hline \hline Full Name & Gazi Zahirul Is & Sur Name & Gazi \\
\hline Father's & Gazi Abdul Me & Sex & MALE \\
Name & & E-Mail & zahircuet@gn \\
\hline $\begin{array}{l}\text { Date of } \\
\text { Birth }\end{array}$ & 04/05/1982 & & \\
\hline \hline $\begin{array}{l}\text { Mailing } \\
\text { Address }\end{array}$ & House: 146, Road: 1, Shugandr_en & Marital & \\
\hline
\end{tabular}

International Technology Management Review, October 2009, v2, n1. 


\begin{tabular}{|c|c|c|c|}
\hline $\begin{array}{l}\text { Home } \\
\text { Phone no }\end{array}$ & 031657911 & Mobile No & 0171193782 \\
\hline Religion & Islam & Nationality & Bangladeshi \\
\hline \multicolumn{4}{|c|}{ CAREER \& APPLICATOIN INFORMATION } \\
\hline $\begin{array}{l}\text { Your } \\
\text { Preferred } \\
\text { Level of } \\
\text { Position }\end{array}$ & \multicolumn{3}{|c|}{$\mathbf{C}_{\text {Entry Level }} \mathbf{C}$ Mid Level $\mathbf{C}$ Top Level } \\
\hline $\begin{array}{l}\text { Available } \\
\text { For }\end{array}$ & \multicolumn{3}{|c|}{$\mathbb{C}$ Full Time $\mathbb{C}$ Part Time $\mathbf{C}$ Contract Job } \\
\hline $\begin{array}{l}\text { Present } \\
\text { Salary }\end{array}$ & 15000 & $\begin{array}{l}\text { Expected } \\
\text { Salary }\end{array}$ & 20000 \\
\hline $\begin{array}{l}\text { Ready to } \\
\text { Join }\end{array}$ & $2006-1-1$ & $\begin{array}{l}\text { Have you } \\
\text { applied } \\
\text { before? }\end{array}$ & No \\
\hline $\begin{array}{l}\text { Source of } \\
\text { application }\end{array}$ & $\begin{array}{ll}\mathbb{C} & \text { Newspaper Add } \mathbb{C} \\
\mathbb{C} & \text { Others }\end{array}$ & b Add ${ }$ & ends \\
\hline $\begin{array}{l}\text { Main } \\
\text { Reason for } \\
\text { applying }\end{array}$ & It looks better for me & & $\begin{array}{l} \pm \\
\square \\
+1\end{array}$ \\
\hline $\begin{array}{l}\text { Future } \\
\text { Plan }\end{array}$ & Taking Masters degree & & $\begin{array}{r}+ \\
\\
\end{array}$ \\
\hline & Submit & & \\
\hline
\end{tabular}

Source: Developed for this paper

After submitting first portion successfully then second portion of the form will come. Figure 7 shows second portion which required information about academic and training information of the candidate. After filling the fields of second portion of the form, candidate has to submit it. If it is successfully submitted then last portion experience information will come. 
Figure 7: Second portion of the of the job_applicant form

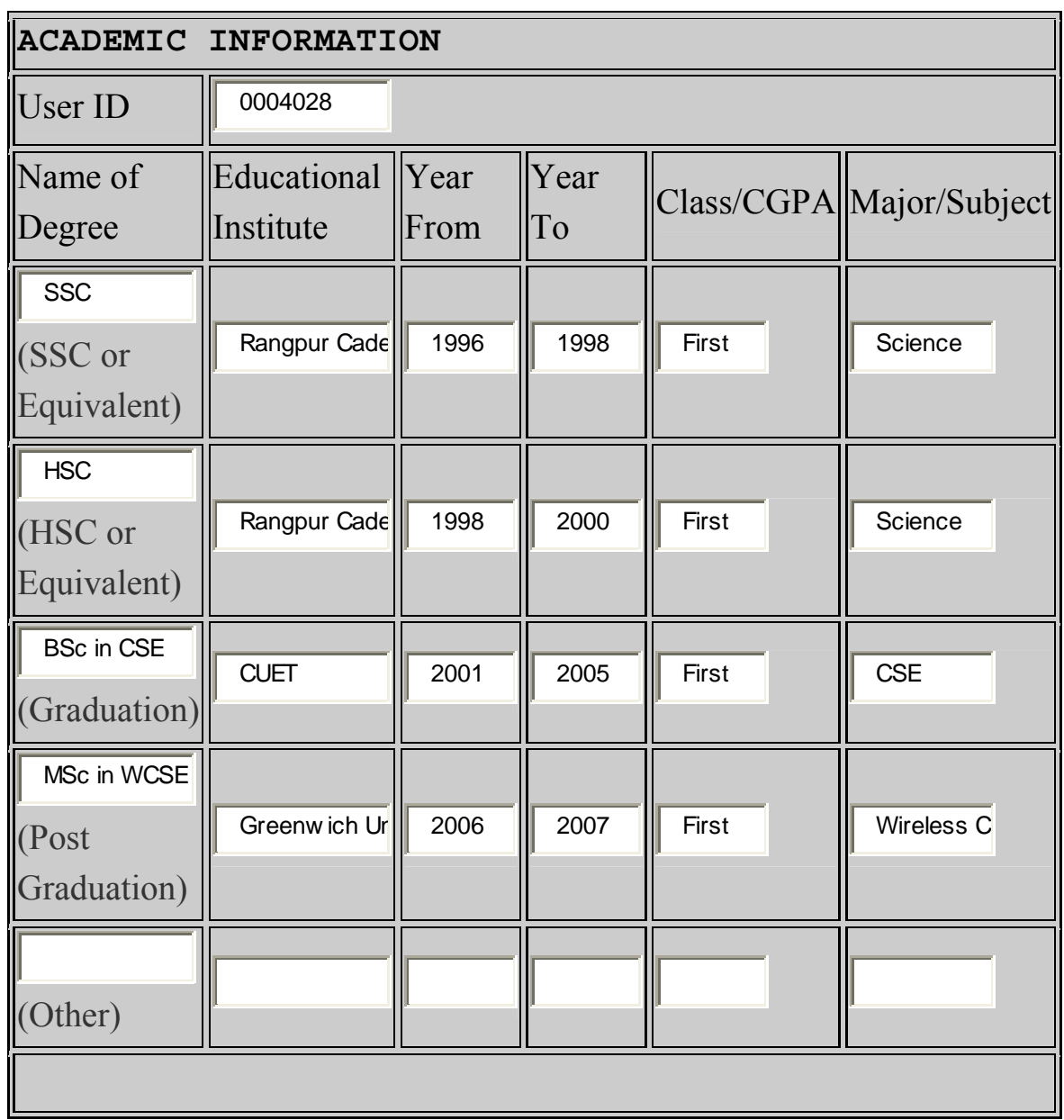

\begin{tabular}{|c|c|c|c|}
\hline \multicolumn{4}{|c|}{ TRAINING INFORMATION } \\
\hline Title & $\begin{array}{l}\text { Completion } \\
\text { Year }\end{array}$ & Institute & $\begin{array}{l}\text { Topics } \\
\text { Covered }\end{array}$ \\
\hline CCNA & 2005 & New Horizon & IP, RIP, OSPF \\
\hline Linux & 2006 & Daffodil Educé & Shell, Red hat \\
\hline
\end{tabular}

Bottom of Form

Source: Developed for this paper

At last, final and third portion of the form which required information about work experience will appear, if previous portion submitted accurately. Figure 8 shows the experience information portion. If this portion is completed and submitted successfully then all required 
information of the job application form would be gathered and stored into the main database of DCC.

Figure 8: Last portion of the of the job_applicant form

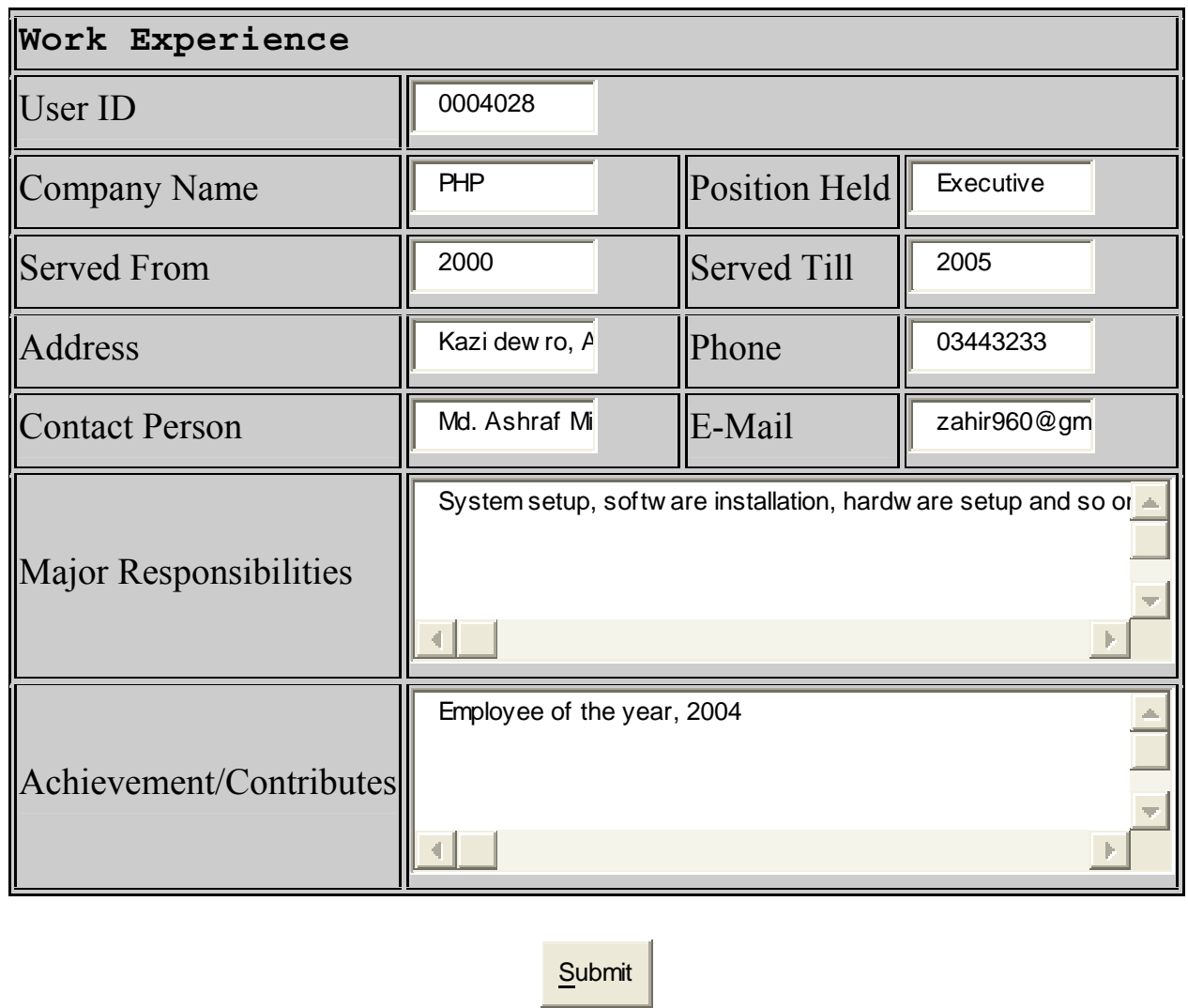

Source: Developed for this paper

\section{System implementation}

We focus to develop a flexible system as possible for developing our e-governance model. A cost effective and efficient system should be implemented to suit existing infrastructure. Special concentration should be given for rural areas due to weaker communication infrastructure in villages. Client and user software should be developed as simple as possible. Software interfaces and forms should provide information also in Bengali, so that rural people can easily understand the information and communicate with the government. Data can be submitted either in online or offline. Offline data submission reduces operational cost and also very flexible for a noisy and low bandwidth network. Data can be uploaded to central database 2 or 3 times in a day or more than that as required and availability of good connection. People can fill up the application forms at their nearest kiosk. After submission of the form he would be given a unique token number from DCO or CCO for identification of the submitted application. Local kiosks are also capable of delivering status information for International Technology Management Review, October 2009, v2, n1. 
online queries from central databases. Kiosks should also provide all of the facilities as people required specially for cities such as scanner, printer, web camera etc.

\section{Constraints and recommendations}

There are some infrastructural constraints in rural areas which should be carefully considered before implementing e-governance. So, project designer needs to measure the success rate in terms of technological breakthrough of the system under design (Rajaraman, 2005).

In rural areas often the telephone lines are idle due to some technical failure or too noisy for computer data transmission. Network bandwidth, data speed and a noise free network connection are desired for on-line data transmission. To reduce the cost of operation of dialup ICT network and getting this dial-up connectivity active the form submission process should made offline also. To reduce the bandwidth, only data fields could be transmitted to store it in the central database. These types of communication problems may not arise in city areas.

To establish e-governance following principles should be obeyed:

- Consider rural and urban infrastructure separately to implement the project

- Focus on disadvantaged communities, who otherwise will be excluded

- Provide that information or service which otherwise will not be provided

- Focus on utilizing and where possible building upon what is existing rather than thrusting a new intervention

- Create an outcome which in absence of ICT will not be produced efficiently or timely.

If the above guiding principles are followed, then it is more likely that ICT for development project will:

- Be accepted and used by the disadvantaged community

- Sustain itself and leverage symbiotic participation from other agents in the society

Last but not the least; one can never overestimate the 2 reasons why ICT for development projects can fail even with the best of intentions and innovations. These are:

i. Lack of information sharing culture among people and institutions. For instance, when people and institutions, including media, NGOs, government officials are more inclined to restricting information flows rather than enhancing it.

ii. General in apathy of the people and institutions to act upon information available to them. For instance, when the acceptance of corrupt practices or criminalization of politics is so deeply embedded in the society that people and institution fail to act against corrupt practices and criminal scandals unearthed through e-Governance.

\section{Conclusion}

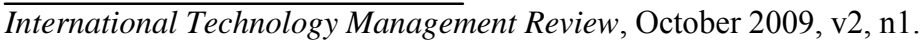


The term e-governance is of recent origin and has become the buzzword in all developing countries (Prasad, 2003). In fact, it is the use of Information and Communication Technology (ICT) for redesigning the traditional mode of governance, through better coordination and sharing of power among different components of government; thus taking care of the traditional problems of governance. The lack of information and communication infrastructure results in people having to waste time and money (Das, Sharma, Gogoi, 2004), (UNESCO Communication and Information, 2005). Lack of clarity in processes, and corruption and mismanagement in systems and operations, is rampant. In this context, Information and Communication Technologies (ICTs) can play a significant role in making information available at a reasonable cost. ICTs promise to provide innovative solutions to the problems of poverty and inequality by accelerating development and introducing transparency into systems and operations.

At last, establishing e-governance is utmost important for our country. In this paper, we proposed a comprehensive and cost effective model of e-governance considering existing ICT infrastructure of Bangladesh. We hope that this paper could provide important guidelines and information to government and others who deal with e-governance.

\section{References}

Andrew S. Tanenbaum 2004, Computer Networks, 4th edition. Cisco Systems Inc 2005, viewed 25 October 2005, <http://www.cisco.com/>

Dave W. Mercer, Allan Kent, Steven D. Nowicki, David Mercer, Dan Squier, Wankyu Choi 2004, Beginning PHP5.

DG Communities 2005, viewed 5 November 2005, $<$ http://topics.developmentgateway.org/egovernment?goo=1554>

Dhaka City Corporation 2005, viewed 20 October 2005, <http://www.dhakacity.org/>

DigitalGovernance.org Initiative 2005, viewed 25 October 2005,

$<$ http://216.197.119.113/artman/publish/index1.shtml>

Douglas E. Comer 2004, Computer Networks and Internets, 4th edition.

E-Democracy, E-Governance and Public Network 2005, viewed 5 November 2005, $<$ http://www.publicus.net/articles/edempublic network.html $>$

Global Information Infrastructure Commission 2005, viewed 5 November 2005, $<$ http://www.giic.org $>$

International Technology Management Review, October 2009, v2, n1. 
Jeffrey A. Hoffer, Mary B. Prescott, Fred R. McFadden 2004, 'Modern Database Management', 6th edition.

Md. Shahidul Islam, M. Ismail Jabiullah, M. Lutfar Rahman 2004, 'M- Commerce Infrastructure Design and Development: Bangladesh Perspective', Paper No- 074, ICCIT.

Narasimha Murthy D., Prasanna Kumar R.V. 2003, 'Software Architectural Design Model For e-Governance Systems', IEEE.

Pankaj Sharma 2005, E-Governance, 2nd edition.

Sanjib Das, L. N. Sharma, A. K. Gogoi 2004, 'Enabling E-Governance for Low Bit Rate Network through Rural ICT Infrastructures in Indian Villages', Paper No-075, ICCIT.

the-south-asian.com 2005, viewed 28 October 2005, <http://www.the-south-asian. com/Oct2001/E-Governance.htm>

T. V. Prasad 2003, ‘e-Governance and Standardization', IEEE.

UNESCO Communication and Information 2005, viewed 28 October 2005,

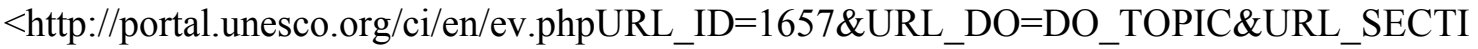
$\mathrm{ON}=201 . \mathrm{html}>$

V. Rajaraman 2005, Analysis and Design of Information Systems, 2nd edition.

(C) 2009 Academic Global Publications P/L. This work is copyright. You may download and print only one paper copy from this electronic file for your personal use only, from which you may not make any further paper copies.

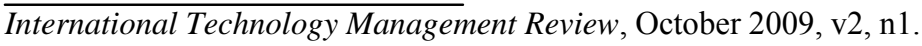

